\title{
Original
}

\section{Advanced Analysis to Distinguish between Physical Decrease and Inactivation of Viable Phages in Aerosol by Quantitating Phage-Specific Particles}

\author{
NORIKO SHIMASAKI ${ }^{*}$, YASUHIRO NOJIMA ${ }^{2}$, MASAYA SAKAKIBARA ${ }^{2}$, \\ RITSUKO KIKUNO ${ }^{2}$, CHIORI IIZUKA ${ }^{2}$, AKIRA OKAUE ${ }^{2}$, SHUNJI OKUDA ${ }^{3}$, \\ AND KATSUAKI SHINOHARA ${ }^{1}$ \\ 'National Institute of Infectious Diseases, 4-7-1 Gakuen, Musashimurayama-shi, Tokyo, Japan \\ ${ }^{2}$ Kitasato Research Center for Environmental Science, 1-15-1 Kitasato, Minami, Sagamihara, Kanagawa, Japan \\ ${ }^{3}$ former Kitasato Research Center for Environmental Science \\ Received 8 June, 2017/Accepted 11 October, 2017
}

\begin{abstract}
Recent studies have investigated the efficacy of air-cleaning products against pathogens in the air. A standard method to evaluate the reduction in airborne viruses caused by an air cleaner has been established using a safe bacteriophage instead of pathogenic viruses; the reduction in airborne viruses is determined by counting the number of viable airborne phages by culture, after operating the air cleaner. The reduction in the number of viable airborne phages could be because of "physical decrease" or "inactivation". Therefore, to understand the mechanism of reduction correctly, an analysis is required to distinguish between physical decrease and inactivation. The purpose of this study was to design an analysis to distinguish between the physical decrease and inactivation of viable phi-X174 phages in aerosols. We established a suitable polymerase chain reaction (PCR) system by selecting an appropriate primer-probe set for PCR and validating the sensitivity, linearity, and specificity of the primer-probe set to robustly quantify phi-X174-specific airborne particles. Using this quantitative PCR system and culture assay, we performed a behavior analysis of the phage aerosol in a small chamber $\left(1 \mathrm{~m}^{3}\right)$ at different levels of humidity, as humidity is known to affect the number of viable airborne phages. The results revealed that the reduction in the number of viable airborne phages was caused not only by physical decrease but also by inactivation under particular levels of humidity. Our study could provide an advanced analysis to differentiate between the physical decrease and inactivation of viable airborne phages.
\end{abstract}

Key words : Virus aerosol / Phi-X174 phage / Quantitative polymerase chain reaction (PCR) / Physical decrease / Inactivation.

\section{INTRODUCTION}

Pathogens in the air have a high risk of spreading infections such as influenza virus worldwide. Recent studies have investigated the performance of air-cleaning products against airborne pathogens (Nishimura, 2011; Ogata et al., 2016).

To evaluate the reduction in airborne viruses brought about by an air cleaner, a standard test method was

*Corresponding author. Tel: +81-42-561-0771, Fax: +81-42561-6156, E-mail : shima (a) nih.go.jp established using a safe bacteriophage instead of pathogenic viruses; the reduction in airborne viruses is determined by counting the number of viable airborne phages by the culture method, after operating the air cleaner (JEM1467, 2015).

The reduction in the number of viable microbes might be due to "physical decrease" or "inactivation"; physical decrease refers to the removal of microbe particles from the air (e.g., through filter adsorption), while inactivation indicates that microbe particles exist in the air, but have lost their infectivity.

In a previous study, we analyzed the behavior of bacte- 
rial aerosols in an experimental chamber and concluded that it was necessary to distinguish between the physical decrease and inactivation of airborne microbes when reducing viable microbial levels (Okuda et al., 2008). We speculated that understanding the mechanism behind the reduction was important for proper usage of air-cleaning products. In the case of physical decreases, it is necessary to consider the secondary contamination of the destination of the viable microbes. In the case of inactivation, mutants or revertants of the microbes must be considered. This distinction is especially important when developing new devices for cleaning the air. Therefore, a behavior analysis that distinguishes between the physical decrease and inactivation of airborne phages is necessary.

In order to distinguish between the physical decrease and inactivation of airborne microbes by laboratory evaluation, it is necessary to quantify the total number of microbial particles, regardless of the infectivity titer. As a useful method for measuring the amount of virus-specific particles in an aerosol, the polymerase chain reaction (PCR) targeting a virus-specific nucleic acid region has been used in aerosol studies (Nakata et al., 2010; Turgeon et al., 2014). When choosing the PCR target, it is necessary to ensure that it is as resistant as possible to DNA-damaging factors such as UV.

Here, we performed a behavior analysis to distinguish between the physical decrease and inactivation of viable phages in aerosols, using phi-X174 in a small chamber $\left(1 \mathrm{~m}^{3}\right)$. To robustly quantify phi-X174-specific airborne particles, we selected and used a primer-probe set for PCR that was almost entirely unaffected by UV, which may damage nucleic acids. We confirmed the sensitivity, linearity, and specificity of the selected primer-probe set even in the presence of other environmental microbes. Using this quantitative PCR system and culture assay, we performed a behavior analysis of a phage aerosol at different levels of humidity, which is known to affect the viable number of airborne phi-X174 phages (Nakanishi et al., 2012; Verreault et al., 2015).

\section{MATERIALS AND METHODS}

\section{Test phage preparation}

The phi-X174 phage (ATCC 13706-B1 or NBRC 103405) and Escherichia coli (ATCC 13706 or NBRC 13898) were prepared, as described in a previous study (Shimasaki et al., 2016a), with some modifications. The host $E$. coli was grown in a nutrient broth (NB; Difco ${ }^{\mathrm{TM}}$, Becton, Dickinson and Company, NJ, USA) with 0.5\% $\mathrm{NaCl}(0.5 \% \mathrm{NaCl}-\mathrm{NB})$ and $2 \mathrm{mM} \mathrm{CaCl} 2$ at $36^{\circ} \mathrm{C}$ overnight, and the cell density was adjusted to $10^{8}-10^{9}$ colony-forming units (CFU)/mL. The phi-X174 phage at a density of $10^{5}-10^{6}$ plaque-forming units (PFU) $/ \mathrm{mL}$ was mixed with an equal volume of the host suspension, and 2 volumes of $0.5 \% \mathrm{NaCl}-\mathrm{NB}$ containing $0.5 \%$ agar (Difco ${ }^{\mathrm{TM}}$, Becton, Dickinson and Company) were added. The mixture was poured onto a plate of nutrient agar (NA; Difco ${ }^{\mathrm{TM}}$, Becton, Dickinson and Company). After cultivation for $18 \mathrm{~h}$ at $36^{\circ} \mathrm{C}$, the upper soft-agar layer containing phi-X174 phages was collected and transferred into a stomacher bag. The bag was stomached for 2 min to crush the soft-agar and then warmed at $36^{\circ} \mathrm{C}$ for $1 \mathrm{~h}$. The lysate in the bag was transferred into centrifuge tubes and centrifuged at $2,380 \times g$ for 10 min. The supernatant was collected and centrifuged twice. The final supernatant was filtered using a membrane filter (0.22 $\mu \mathrm{m}$ pore size; Stericup, Millipore, Darmstadt, Germany) and stored below $-80^{\circ} \mathrm{C}$ until it was used for the test. The stock phi-X174 phage was at a concentration of approximately $1 \times 10^{10} \mathrm{PFU} / \mathrm{mL}$.

\section{Phage plaque assay}

The phage titer was determined using a soft-agaroverlaid plaque assay, as previously described (Shimasaki et al., 2016a). Briefly, the assay fluid was 10 -fold serially diluted with PBS, and $0.2 \mathrm{~mL}$ of each serially diluted assay fluid sample, along with the undiluted sample, was mixed with $0.2 \mathrm{~mL}$ of the host $E$. coli (ca. $10^{9} \mathrm{CFU} / \mathrm{mL}$ ) and added to tubes with $4 \mathrm{~mL}$ of $0.5 \% \mathrm{NaCl}-\mathrm{NB}$ containing $0.5 \%$ agar. After gentle mixing, the suspension was poured into three plates of NA. After cultivation for $18 \mathrm{~h}$ at $36^{\circ} \mathrm{C}$, the plaques on the plates were counted.

\section{Quantification of the viral amount using real-time PCR (qPCR)}

We investigated the three sets (sets $A, B$, and $C$ ) of primers and probes listed in Table 1, all obtained from previous studies (Brown et al., 2010; Myers et al., 2009; Turgeon et al., 2014). The phi-X174 genomes of all the samples were quantified without DNA extraction, as previously reported (Turgeon et al., 2014). We used a real-time PCR system (Model 7500Fast or Model 7500, Applied Biosystems Japan Ltd., Tokyo, Japan) for quantification by PCR assay. The assay components and the PCR program were set according to a previous study (Myers et al., 2009), with some modifications. Briefly, the assay components were as follows: $5 \mu \mathrm{L}$ of phage sample, $2 \mu \mathrm{L}$ of forward primer at $10-\mu \mathrm{mol} / \mathrm{L}$ $(\mu \mathrm{M}), 2 \mu \mathrm{L}$ of reverse primer at $10-\mu \mathrm{M}, 1 \mu \mathrm{L}$ of duallabeled probe at $5-\mu \mathrm{M}$, and $10 \mu \mathrm{L}$ of $2 \times$ Taqman universal Master MIX (Applied Biosystems). The total volume was $20 \mu \mathrm{L} /$ well for the 7500 Fast. For the 7500 , each reagent or sample used was 2.5 volumes of the volume used in 7500Fast, and the total volume was 50 $\mu\llcorner/$ well.

The PCR program was as follows: hold for 2 min at 
TABLE 1. Primers and probes used in this study.

\begin{tabular}{|c|c|c|c|c|c|c|}
\hline Set & type & Position* & Sequence ( $5^{\prime}$ to $3^{\prime}$ ) & Modification & Amplicon size & Reference \\
\hline \multirow{3}{*}{ A } & Forward & $400-424$ & TTACTgAACAATCCgTACgTाTCCA & - & \multirow{3}{*}{$67 \mathrm{bp}$} & \multirow{3}{*}{ Brown et al., 2010} \\
\hline & Reverse & $466-457$ & ACggCAgAAgCCTgAATgAg & - & & \\
\hline & Probe & $427-443$ & CCgCTIggССTCTATT & $\begin{array}{l}\text { 5' } \mathrm{FAM}- \\
\text { 3' } \mathrm{BHQ}-1\end{array}$ & & \\
\hline \multirow{3}{*}{$\mathrm{B}$} & Forward & $508-531$ & ACAAAgTाTggATTgCTACTgACC & - & \multirow{3}{*}{$123 \mathrm{bp}$} & \multirow{3}{*}{ Turgeon et al., 2014} \\
\hline & Reverse & $630-609$ & CggCAgCAATAAACTCAACAgg & - & & \\
\hline & Probe & $533-556$ & СтCTCgTgCTCgTCgCTgCgTTgA & $\begin{array}{l}\text { 5' FAM - } \\
\text { 3' } \mathrm{BHQ}-1\end{array}$ & & \\
\hline \multirow{3}{*}{$\mathrm{C}$} & Forward & $648-668$ & CATCCCgTCAACATTCAAACg & - & \multirow{3}{*}{$73 \mathrm{bp}$} & \multirow{3}{*}{ Myers et al., 2009} \\
\hline & Reverse & $720-697$ & CgCCATTAATAATgПITCCgTAA & - & & \\
\hline & Probe & $674-690$ & TCTCATCATggAAggCg & $\begin{array}{l}5^{\prime} \mathrm{FAM}- \\
3^{\prime} \mathrm{BHQ}-1\end{array}$ & & \\
\hline
\end{tabular}

\footnotetext{
*The position was based on complete genome 5386 nucleotides of Enterobacteria phage phi-X174 sensu lato (NCBI Reference Sequence NC_001422.1).
}

$50^{\circ} \mathrm{C}$; hold for 10 min at $95^{\circ} \mathrm{C}$; perform 42 amplification cycles of $95^{\circ} \mathrm{C}$ for $15 \mathrm{~s}$ and $60^{\circ} \mathrm{C}$ for $60 \mathrm{~s}$; and then perform fluorescence measurement. For each PCR run, a standard curve was generated in duplicate with the phi-X174 virion DNA (New England Biolabs Inc., MA, USA). Serial 10-fold dilutions, ranging from 2 to $2 \times 10^{7}$ copies per reaction well were used to establish the standard curves. Each sample in duplicate was analyzed using the standard curves to determine the corresponding concentration. All data were analyzed with the software supplied with the machines, and the thresholds were set automatically with the software.

\section{UV irradiation}

One hundred microliters of the test suspension were dropped onto $3.5-\mathrm{cm}$ cell culture dishes (Falcon, Becton, Dickinson and Company) and covered with a thin film (thickness of $0.04 \mathrm{~mm}$, polyethylene) cut into squares of $2 \times 2 \mathrm{~cm}^{2}$. The dishes were placed in a biological safety cabinet under UV light of $0.04 \mathrm{~mW} / \mathrm{cm}^{2}$ with a wavelength of $254 \mathrm{~nm}$ through the film, as measured by a UV meter (Model UVC-254, Lutron Electronic Enterprise Co., Ltd., Taipei, Taiwan), for a predetermined period of time. After UV irradiation for the predetermined time, $1.9 \mathrm{~mL}$ of soybean casein digest lecithin polysorbate broth (SCDLP-B; Eiken Chemical Co., Ltd., Tokyo, Japan) was poured between the film and the dish using a micropipette. The dishes with the SCDLP-B were shaken on a microplate mixer (EM-36, Taitec Co., Saitama, Japan) for $10 \mathrm{~s}$ to wash away the phages from the dish and the film. The washed-out solution was collected and assayed.

\section{Preparation of other bacteria and viruses}

Bacillus subtilis (ATCC 6633), Staphylococcus epidermidis (NBRC 12993), and human adenovirus 3 (strain GB, ATCC VR-3) were used in this study. B. subtilis, S. epidermidis, and human adenovirus 3 were prepared according to a previous report (Shimasaki et al., 2016b), with some modifications. Briefly, the B. subtilis, S. epidermidis, and human adenovirus 3 test suspensions were diluted with PBS such that their densities were $4 \times 10^{7}$ $\mathrm{CFU} / \mathrm{mL}, 4 \times 10^{7} \mathrm{CFU} / \mathrm{mL}$, and $4 \times 10^{7} \mathrm{TCID}_{50} / \mathrm{mL}$, respectively.

\section{Generation and sampling of the phage aerosol in the test chamber}

A schematic diagram of the test chamber is shown in Fig.1. The test chamber $\left(1 \mathrm{~m}^{3}\right.$ in volume, constructed from boards of polyvinyl chloride) was fitted with a nebulizer (NE-C16, Omron Healthcare Co., Ltd., Kyoto, Japan) for generating the aerosol and a midget impinger (based on JIS K 3800:2009) for sampling. Two stirring fans (SERVO CN55B5, Nidec Servo Co., Gunma, Japan) were operated at a wind speed of $1.5 \mathrm{~m} / \mathrm{s}$ in the chamber during the experiment. Two test pieces (polyvinyl chloride, $7.5 \times 15 \mathrm{~cm}^{2}$ each) were placed at the center of the bottom of the test chamber for harvesting of the falling virus particles. During the experiment, a light-scattering particle counter (Model 3886, Kanomax Japan, Osaka, Japan) was used to monitor the concentration of particles in the test chamber at a flow rate of $2.83 \mathrm{~L}$ air/min, based on our previous report (Shimasaki et al., 2015). The number of particles in each size range was calculated by subtraction, i.e., 0.3-0.5 $\mu \mathrm{m}$ particles $=\geqq 0.3 \mu \mathrm{m}$ particles $-\geqq 0.5 \mu \mathrm{m}$ particles. Before generating the aerosols, $\geqq 1 \mu \mathrm{m}$ particles were confirmed 


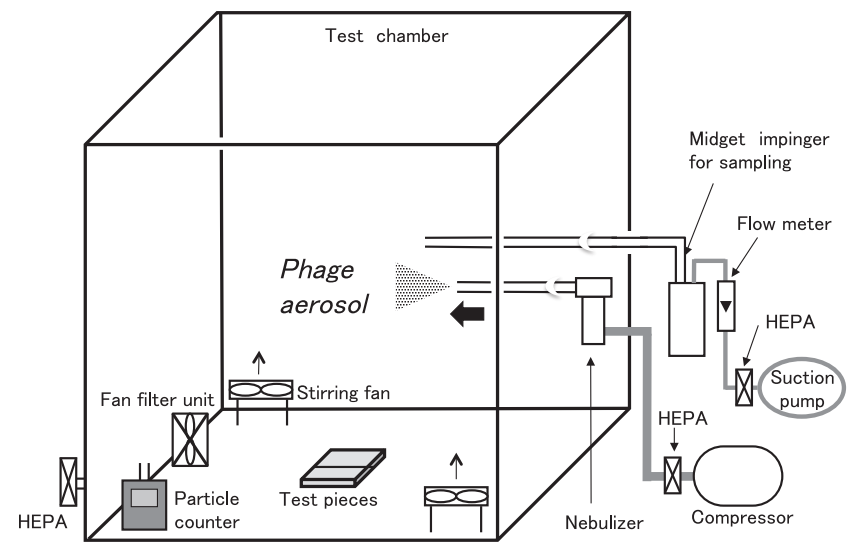

FIG. 1. Arrangement of the test chamber.

The test chamber ( $1 \mathrm{~m}^{3}$ in volume) was fitted with a nebulizer for generating the aerosol and a midget impinger. Two stirring fans were operated in the chamber. During the experiment, a light-scattering particle counter was used to monitor the concentration of particles in the chamber. Before generating the aerosols and after all sampling, particles were removed from the test chamber by running the fan filter unit. The airborne phages were collected for 6 min at $5 \mathrm{~L} / \mathrm{min}$ (30 L in total) with the midget impinger by actuating a suction pump per each sampling. The test pieces were collected after all sampling of airborne phages was completed.

to have been removed from the test chamber by running the fan filter unit. We confirmed that the viable phages in the aerosols were not detected ( $<1$ PFU/30L of air).

Phage aerosols were generated for 1 min (approximately $0.2 \mathrm{~mL} / \mathrm{min}$ ) using the nebulizer with the phage solution diluted 25 -fold with distilled water (DW) at a dispersion rate of $5 \mathrm{~L} / \mathrm{min}$. Subsequently, the aerosols inside the chamber were stirred for 2 min with the fans and then sampled for 6 min at $5 \mathrm{~L} / \mathrm{min}$ (30 L in total) with the midget impinger containing $20 \mathrm{~mL}$ of phosphate buffered saline (PBS, ELMEX Ltd., Tokyo, Japan). Aerosol sampling was performed every 30 min for 120 min for each experiment. The phage amount in the PBS was assayed by plaque assay and qPCR. The qPCR assays were repeated thrice and the average value was calculated. After being exposed to the phage aerosol for $120 \mathrm{~min}$, the test pieces were collected from the chamber and transferred to a stomacher bag with 20 $\mathrm{mL}$ of SCDLP-B. The bag was shaken for 1 min to wash away the phages from the test pieces. The washed-out solution was assayed. The temperature and $\mathrm{RH}$ in the test chamber were measured with a thermo-hygrometer (Ondotori TR-72wf with a THA-3001 sensor; T\&D, Nagano, Japan). All experiments were conducted at $19-22^{\circ} \mathrm{C}$. The relative humidity $(\mathrm{RH})$ in the aerosol test chamber was set to $40 \%, 60 \%, 78 \%$, or above $95 \%$. The nebulization of the phage suspension did not cause any changes in the humidity.

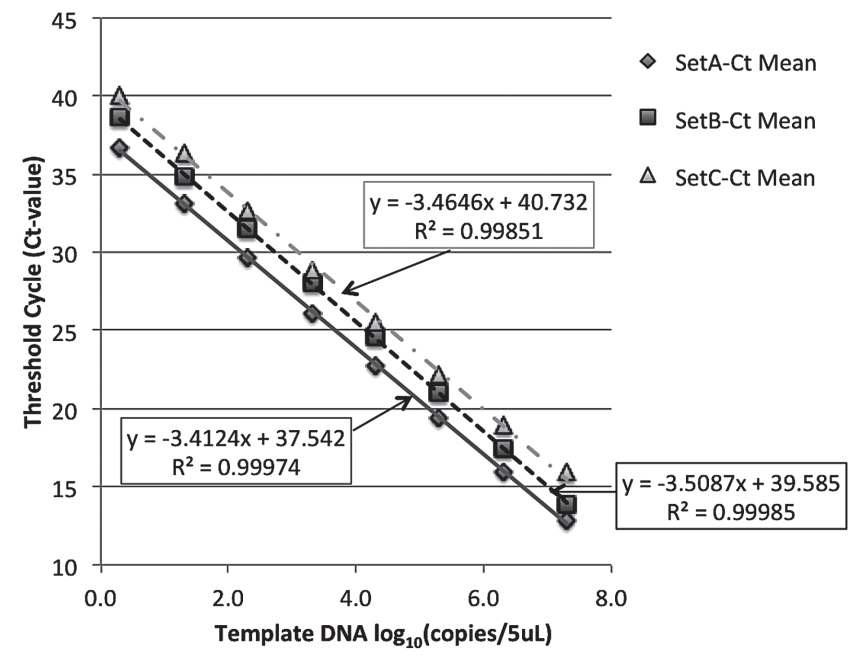

FIG. 2a. Comparison of standard curves.

Using virion DNA, standard curves of each primer-probe set are shown, representing the average of 3 repeated assays.

\section{RESULTS}

\section{Selection of an appropriate primer-probe set for qPCR}

We compared the standard curves of the virion DNA from 2 to $2 \times 10^{7}$ copies obtained using three primerprobe sets (Table 1), after three separate measurements (Fig.2a). The results showed that the standard curve of set $A$ had the least $C t$ values for all copies, suggesting that the PCR reactivity was fastest in set $A$, among the three sets. The mean of the relative standard deviation (RSD) in set A was 1.6\%, while that in sets B and $\mathrm{C}$ was $2.6 \%$ and $1.7 \%$, respectively. Next, as the PCR method quantifies nucleic acids in a target region with a primer, it is preferable for the target regions of each primer-probe set to be as stable as possible against inactivation. UV is considered a severe factor under normal circumstances. We treated the virion DNA in PBS with UV irradiation for 2, 5, 10, and $20 \mathrm{~min}$, and compared the primer-probe sets with the PCR target regions that were damaged by the UV (Fig.2b). The results showed that sets $A$ and $C$ were more resistant to UV than set $B$. Therefore, set $A$ was considered most suitable for QPCR and was selected for subsequent studies. Additionally, the phi-X174 phages diluted with PBS were subjected to UV irradiation for $0.5,1,2$, and $5 \mathrm{~min}$, and then tested by the plaque assay and qPCR (Fig.2c). It was confirmed that UV irradiation did not physically decrease the number of the viable phages, but only inactivated them, because the infectious titer decreased drastically, although the phage DNA amount hardly changed. 


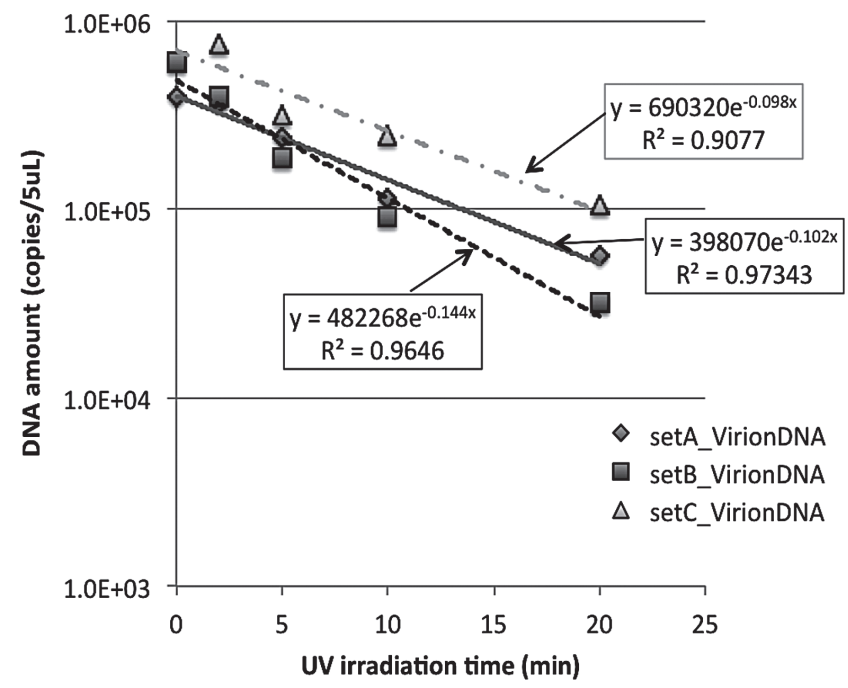

FIG. 2b. Comparison of DNA copies detected after UV irradiation.

Using virion DNA, DNA copies detected by each primer-probe set are shown.

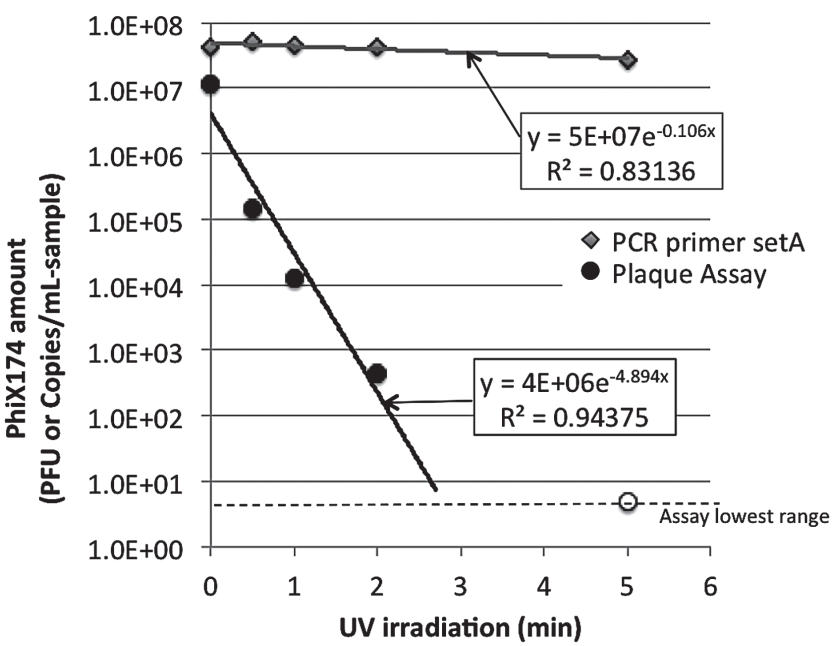

FIG. 2c. Comparison of DNA copies and plaques detected after UV irradiation.

Using phi-X174 phage, DNA copies detected by each primerprobe set and plaques detected by culture assay are shown.

\section{Sensitivity of the qPCR assay for phi-X174 phages}

Based on a previous report (Yoneyama et al., 2007), we measured the sensitivity of the qPCR assay. The phi-X174 virion DNA was serially diluted 4-fold, between $4^{2}$ and $4^{-2}$ copies $/ 5 \mu \mathrm{L}$, and eight or 16 wells for each dilution were then tested (Table 2). The 50\% detection limit was calculated statistically to be achieved at a DNA concentration of $4^{-0.38}$, i.e., 0.6 copies $/ 5 \mu \mathrm{L}$.

\section{Linearity of the qPCR assay for phi-X174 phages}

To investigate the quantitative range and linearity of
TABLE 2. Sensitivity of qPCR assay for detecting phi-X174 phage DNA.

\begin{tabular}{ccc}
\hline $\begin{array}{c}\text { Phage DNA } \\
\text { (Copies/5uL) }\end{array}$ & $\begin{array}{c}\text { No. of positive } \\
\text { samples/no. of } \\
\text { tested samples }\end{array}$ & Positive (\%) \\
\hline $4^{2}$ & $8 / 8$ & 100 \\
$4^{1}$ & $16 / 16$ & 100 \\
$4^{0}$ & $11 / 16$ & 69 \\
$4^{-1}$ & $3 / 16$ & 19 \\
$4^{-2}$ & $0 / 16$ & 0
\end{tabular}

The 50\% detection limit was calculated statistically to be achieved at a DNA concentration of $4^{-0.38}$, which was 0.6 copies $/ 5 \mu \mathrm{L}$.

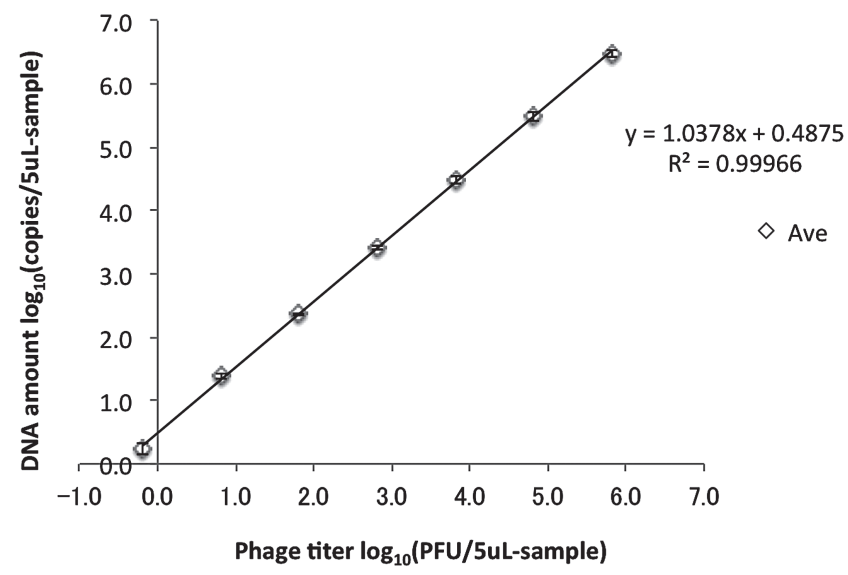

FIG. 3. Linearity of the $\mathrm{qPCR}$ assay for phi-X174 phages. Using phiX174, the titer of the phage was varied with 10 -fold dilution ranging from $6.5 \times 10^{5}$ to $6.5 \times 10^{-1} \mathrm{PFU} / 5 \mu \mathrm{L}$ and assayed using qPCR in three independent experiments. The average for each titer is shown. Error bars denote standard deviation.

the $\mathrm{qPCR}$, the phi-X174 phage solution was diluted 10 -fold from $6.5 \times 10^{5}$ to $6.5 \times 10^{-1} \mathrm{PFU} / 5 \mu \mathrm{L}$ and assayed using qPCR in three independent experiments. All of the results showed linearity at this dose of phi-X174 phages, with each $R^{2}$ value higher than 0.99. The average phage DNA amount, as determined by the assay, was proportional to the dose of phi-X174 (goodness-of-fit of simple linear regression; $R^{2}=0.99966$ ) (Fig.3).

\section{Specificity of the qPCR assay for phi-X174 phages in the presence of other environmental microbes}

The specificity of the qPCR assay for phi-X174 phages was investigated using other environmental microbes, including $B$. subtilis $\left(10^{5} \mathrm{CFU} / 5 \mu \mathrm{L}\right)$, S. epidermidis $\left(10^{5}\right.$ $\mathrm{CFU} / 5 \mu \mathrm{L})$, and human adenovirus $3\left(10^{5} \mathrm{TCID}_{50} / 5 \mu \mathrm{L}\right)$, as contaminants in an aerosol test (Table 3 ). These 
TABLE 3. Specificity of the qPCR assay for phi-X174 phages in the presence of environmental microbes.

\begin{tabular}{ccccc}
\hline & \multicolumn{3}{c}{ phi-X174-specific DNA amount (copies/5uL of the sample) in the qPCR } \\
\cline { 2 - 5 } & phi-X174 & $\begin{array}{c}\text { phi-X174 }+ \\
\text { B. subtilis }\end{array}$ & $\begin{array}{c}\text { phi-X174 }+ \\
\text { S. epidermidis }\end{array}$ & $\begin{array}{c}\text { phi-X174 + } \\
\text { Human } \\
\text { Adenovirus 3 }\end{array}$ \\
\hline Ave. $(\mathrm{n}=3)$ & $1.1 \times 10^{5}$ & $1.9 \times 10^{5}$ & $1.5 \times 10^{5}$ & $1.5 \times 10^{5}$ \\
S.D. & $5.3 \times 10^{4}$ & $2.1 \times 10^{4}$ & $2.4 \times 10^{4}$ & $2.8 \times 10^{4}$ \\
$t$-test & - & $P=0.152$ & $P=0.334$ & $P=0.102$ \\
\hline
\end{tabular}

As models of environmental microbes, we used Bacillus subtilis, Staphylococcus epidermidis, and human adenovirus 3. In the presence of these microbes, the phi-X174 phages (about 1 $\times 10^{5}$ copies $/ 5 \mu \mathrm{L}$ ) were assayed by the $\mathrm{gPCR}$. The values in the table are the average (Ave.), the standard deviation (S.D.) of three measurements. The determined values were analyzed by a $t$-test between phi-X174 alone and phi-X174 with the different microbes. In the presence of these microbes, there were no significant differences in the amount of phi-X174-specific DNA ( $t$-test: $P>0.1)$.

microbes, when used individually, showed no amplification with this qPCR assay. Equal volumes of each microbe solution were mixed with phi-X174 virion DNA (approximately $1 \times 10^{5}$ copies $/ 5 \mu \mathrm{L}$ ) and assayed thrice by the $\mathrm{qPCR}$. The results showed that the assay detected almost the same concentration of the phage DNA since there were no statistically significant differences despite the presence of the other microbes, indicating that the GPCR assay was specific for phi-X174 phages even in the presence of other environmental microbes.

\section{Behavior analysis of the phage aerosol at different levels of humidity to distinguish between physical decrease and inactivation}

Using GPCR and plaque assay, the phi-X174 aerosol behavior was analyzed in the test chamber at different levels of relative humidity to distinguish between inactivation and physical decrease in the number of airborne phages. The aerosols were generated under $40 \% \mathrm{RH}$, $60 \% \mathrm{RH}, 78 \% \mathrm{RH}$, or above $95 \% \mathrm{RH}$; the nebulized phage solutions contained $5.8 \times 10^{8}, 4.8 \times 10^{8}, 4.4 \times$ $10^{8}$, and $6.2 \times 10^{8} \mathrm{PFU} / \mathrm{mL}$, respectively. The concentration of the 0.3-0.5- $\mu \mathrm{m}$ particles increased mainly in the test chamber. When nebulization was independently performed thrice at $40 \% \mathrm{RH}$, the variation in the sampling at 0 min was $0.2 \log _{10}$ (PFU/3OL of air) in double standard deviation.

The results showed that the decrease in phage particles at $40 \% \mathrm{RH}, 60 \% \mathrm{RH}$, and $78 \% \mathrm{RH}$ were similar, as the slope of the simple linear regression for the log-PCR values were almost the same $(40 \% \mathrm{RH},-0.008 ; 60 \%$ $\mathrm{RH},-0.01$; and $78 \% \mathrm{RH},-0.0075$ ) (Fig.4a, 4b, 4c). More airborne phages were inactivated at $60 \% \mathrm{RH}$ than at $40 \% \mathrm{RH}$, because the slope of the simple linear regression for the log-plaque values at $60 \% \mathrm{RH}$ was twice that at $40 \% \mathrm{RH}(40 \% \mathrm{RH},-0.0106 ; 60 \% \mathrm{RH}$, -0.0203 ), while the slope of the simple linear regression for log-PCR was the same at $40 \%$ and $60 \% \mathrm{RH}$.

In contrast, airborne phages were inactivated less at $78 \% \mathrm{RH}$, compared to $40 \% \mathrm{RH}$, as evidenced by the similar slopes of the simple linear regression for logplaque values in the two conditions $(40 \% \mathrm{RH},-0.0106$; $78 \% \mathrm{RH},-0.011)$. Similarly, the slope of the simple linear regression for log-PCR was the same at 40\% and $78 \% \mathrm{RH}$. When a separate experiment was performed at $40 \% \mathrm{RH}$, the slopes for log-PCR values and logplaque values were reproduced (for log-PCR, -0.008 , for log-plaque, -0.0078), although the viable number at 0 min was different by about $1 \log _{10}$. Moreover, it was observed that the phage particles in the aerosol did not undergo physical decrease, and viable airborne phages were not inactivated, at above 95\% $\mathrm{RH}$; the slopes of the simple linear regression for the log-PCR values and log-plaque values at above $95 \% \mathrm{RH}$ were -0.0038 and -0.0056 , respectively (Fig.4d).

Furthermore, the amount of phages that adhered to the test piece surfaces was analyzed. It was found that similar amounts of viral particles had adhered onto the surfaces at all levels of humidity studied $(40 \% \mathrm{RH}, 1.8$ $\times 10^{6} ; 60 \% \mathrm{RH}, 2.3 \times 10^{6}$; and $78 \% \mathrm{RH}, 2.8 \times 10^{6}$ copies per two test pieces); however, the amount of viable phages at $60 \% \mathrm{RH}$ was lower than that at other levels of $\mathrm{RH}\left(40 \% \mathrm{RH}, 2.6 \times 10^{5} ; 60 \% \mathrm{RH}, 4.5 \times 10^{4}\right.$; and $78 \% \mathrm{RH}, 2.8 \times 10^{5} \mathrm{PFU}$ per two test pieces). These observations suggest that the amount of phages adhering to the surfaces might be correlated with the amount of airborne phages. When the amount of phages adhering to the surfaces at 0 min under $40 \% \mathrm{RH}$ was analyzed, it was found to be almost the same as that at 120 min (data not shown).

In addition, when another preparation lot of phages 

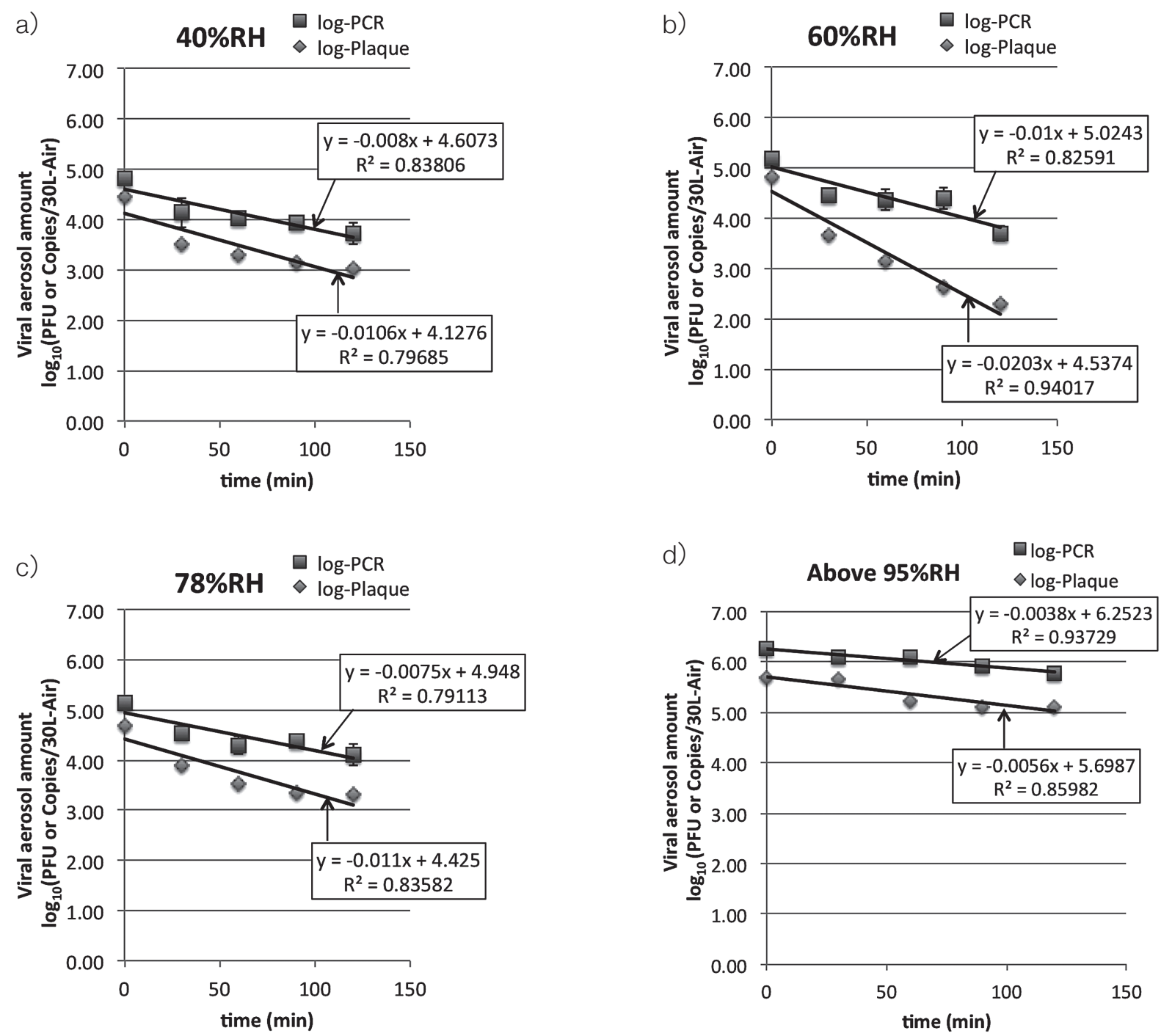

FIG. 4. a) Behavior analysis of viral aerosol at $40 \% \mathrm{RH}$. b) Behavior analysis of viral aerosol at $60 \% \mathrm{RH}$. c) Behavior analysis of viral aerosol at $78 \% \mathrm{RH}$. d) Behavior analysis of viral aerosol at above $95 \% \mathrm{RH}$.

The amount of phage aerosol was collected and assayed every 30 min for 120 min at different levels of humidity (40\%RH, $60 \% \mathrm{RH}, 78 \% \mathrm{RH}$, and above $95 \% \mathrm{RH})$. The values of log-PCR plotted in the graph are the average value of three repeated measurements, and the error bars denote standard deviation.

was diluted 10-fold with DW and nebulized at 50\% $\mathrm{RH}$, it was observed that the phage aerosol detected with $5.0 \times 10^{5} \mathrm{PFU}$ and $2.4 \times 10^{6} \mathrm{copies} / 10 \mathrm{~L}$ of air at $0 \mathrm{~min}$ was rapidly inactivated for $60 \mathrm{~min}$, because viable phages in the aerosol were reduced by approximately $2.7 \log _{10}$ PFU/10L of air while phage particles were not largely reduced by approximately $0.2 \log _{10}$ copies/10L of air.

\section{DISCUSSION}

In this study, we used quantitative PCR system and culture assay to perform a behavior analysis to distinguish between the physical decrease and inactivation of viable phi-X174 phages in aerosols in a small chamber. We selected a primer-probe set, set A, for PCR to robustly quantify phi-X174-specific airborne particles without being adversely affected by UV. Duchaine's research group had used another primer-probe set, set B (Turgeon et al., 2014; Verreault et al., 2015; Turgeon et al., 2016). Ho et al. (2016) had reported that the log reduction by UV of phi-X174 gene copies increased as the specific amplicon length for PCR increased. The primer-probe set we used was more resistant to UV than the ones previously used, as the amplicon size of set A was smaller than that of set B (See Table 1).

Furthermore, our results showed that airborne phi-X174 phages were inactivated at $60 \% \mathrm{RH}$, but not 
at $78 \% \mathrm{RH}$. This was inconsistent with a report by Nakanishi et al. (2012) in which the humidity level enabling easier inactivation was found to be $75 \%$. The only difference between the two studies was the dilution of the phages (our study: 25-fold diluted, Nakanishi's study: 100-fold diluted), although the concentration of phages nebulized into the chamber was almost the same (our study: ca. $5 \times 10^{8} \mathrm{PFU} / \mathrm{mL} \times 0.2 \mathrm{~mL}=10^{8}$ PFU in $1 \mathrm{~m}^{3}$, Nakanishi's study: $2.9 \times 10^{8} \mathrm{PFU} / \mathrm{mL} \times 4.5$ $\mathrm{mL}=1.3 \times 10^{9} \mathrm{PFU}$ in $10 \mathrm{~m}^{3}$ ). As mentioned in a report by Trouwborst and Kuyper (1974), the humidity level enabling easier inactivation differed based on the presence or absence of peptone. In their study, when $0.1 \%$ $(\mathrm{w} / \mathrm{v})$ peptone was added to the phage suspension for aerosolization, the humidity for easier inactivation of phage aerosol shifted from around $80 \% \mathrm{RH}$ to around $40-60 \% \mathrm{RH}$. The phage suspension used in our study contained more peptone than that in Nakanishi's study, as it was diluted less. Therefore, it could be speculated that the difference in the humidity associated with easier inactivation of the phage aerosol in our study and in Nakanishi's could be due to the influence of peptone content.

Incidentally, it was reported that the indoor humidity of houses of Japan was 25\% to above $80 \%$ throughout the year (Zhang et al., 2009). Thus, the humidity conditions in Trouwborst's experiment are considered to cover those of the general environment. As for peptone $0.1 \%(\mathrm{w} / \mathrm{v})$, Trouwborst's experiment used saliva and peptone $0.1 \%(\mathrm{w} / \mathrm{v})$, and revealed that the behavior of viable airborne phages depended on the humidity similarly in both conditions. Furthermore, it has been reported that the total protein content in saliva is 59 to $148 \mathrm{mg} /$ $\mathrm{dL}=0.59$ to $0.148 \%(\mathrm{w} / \mathrm{v}$ ) (Mitsuhashi et al., 2012), indicating that Trouwborst's experiments are considered as well mimic conditions in which viruses are splashed by saliva in the air. Similarly, humidity levels that easily inactivated influenza viruses varied in two previous reports (Harper, 1961; Schaffer et al., 1976). Other factors that affect aerosol behavior will need to be studied in the future.

Currently available standardized tests are not capable of distinguishing between physical decrease and inactivation, when evaluating the reduction in airborne microbes by air cleaners (JEM1467, 2015), because these tests only involve culture assays of airborne microbes. Our results indicated that it is possible to distinguish between physical decrease and inactivation of viable airborne phages through an aerosol test. A behavior analysis to make this distinction would be useful for aerosol testing on model microbes, as it could facilitate the investigation of the mechanism underlying the reduction in the viable number of airborne microbes for developing new air-cleaning devices.
Verreault et al. (2015) described some aerosolized phages that behaved differently under various environmental conditions and highlighted the necessity of carefully selecting viral simulants in bioaerosol studies. When a surrogate microbe is used for evaluation tests, it is worthwhile to verify whether it is an appropriate substitute microbe for the real pathogen, based on the mechanism underlying the reduction. In the case of physical decrease, the similarities in the physical properties of the particle (such as particle size and surface charge) between the test phage and the pathogenic virus may be critical. In contrast, the similarity of the biological sensitivity against materials used for inactivation may be critical in the case of inactivation.

This study had some limitations. If the developed new devices for cleaning the air were to damage the phage DNA more than UV, our quantitative PCR system would not be able to exactly measure the amount of DNA.

Respiratory diseases such as human avian influenza A (H7N9) infection (Liu et al., 2013) and Middle East respiratory syndrome (Bermingham et al., 2012) have become serious problems worldwide. Our results could contribute to future studies for controlling the transmission of airborne pathogens in an actual environment, by studying other environmental factors that affect aerosol behavior and then correlating them with the behavior of real pathogens in aerosols.

\section{ACKNOWLEDGEMENT}

We would like to thank Prof. S. Kato at the Institute of Industrial Science of the University of Tokyo for providing helpful advice.

\section{REFERENCES}

Bermingham, A., Chand, M. A., Brown, C. S., Aarons, E., Tong, C., Langrish, C., Hoschler, K., Brown, K., Galiano, M., Myers, R., Pebody, R. G., Green, H. K., Boddington, N. L., Gopal, R., Price, N., Newsholme, W., Drosten, C., Fouchier, R. A., and Zambon, M. (2012) Severe respiratory illness caused by a novel coronavirus, in a patient transferred to the United Kingdom from the Middle East, September 2012. Euro Surveill., 17, 20290.

Brown, C. J., Zhao, L., Evans, K. J., Ally, D., and Stancik, A. D. (2010) Positive selection at high temperature reduces gene transcription in the bacteriophage $\Phi \times 174$. BMC Evol. Biol., 10, 378 .

Harper, G., J. (1961) Airborne micro-organisms: survival tests with four viruses. J. Hyg. Camb., 59, 479-486.

Ho, J., Seidel, M., Niessner, R., Eggers, J., and Tiehm, A. (2016) Long amplicon (LA)-qPCR for the discrimination of infectious and noninfectious phix174 bacteriophages after UV inactivation. Water Res. 103, 141-148.

JEM1467 (2015) Kuukiseijouki no Huyu-virus nitaisuru Jokyoseinou Hyouka Shiken Houhou (established on 4th, July, 2011) https://www.jema-net.or.jp/Japanese/ha/kuusei/ 
hyoukashiken/hyouka1.pdf. Accessed on 2017.1.17.

Liu, S., Sun, J., Cai, J., Miao, Z., Lu, M., Qin, S., Wang, X., Lv, H., Yu, Z., Amer, S., and Chai, C. (2013) Epidemiological, clinical and viral characteristics of fatal cases of human avian influenza A (H7N9) virus in Zhejiang Province, China. J. Infect., 67, 595-605.

Mitsuhashi, Y. and Ueta, N. (2012) Components of saliva (comparison with serum). (in Japanese) Bulletin 2012 of Teikyo Junior College, 115-120.

Myers, M., B., Mittelstaedt, R., A., and Heflich, R., H. (2009) Using phiX174 DNA as an exogenous reference for measuring mitochondrial DNA copy number. (2009) Biotechniques. 47, 867-869.

Nakanishi, A., Saiki, A., Ota, K., Tanimura, Y., Yasuda, H., and Mizuno, A. (2012) Influence of the Bacteriophage Species and Testing Conditions on the Evaluation of the Inactivation of Airborne Viruses. (in Japanese) Bokin Bobai, 40, 67-74.

Nakata, Y., Sugita, N., and Shimizu, K. (2010) Evaluations of airborne influenza virus inactivated by Circle plasma. (in Japanese) Proceedings of Air Cleaning and Contamination Control Research Workshop on Pre 2010 International Symposium of Contamination Control, ISCC2010, 160-163.

Nishimura, H. (2011) Virological Evaluation of Electrical Devices Advertising Inactivation of Air-borne Influenza Virus. (in Japanese) J. J. A. Inf. D., 85, 537-539.

Ogata, N., Sakasegawa, M., Miura, T., Shibata, T., Takigawa, Y., Taura, K., Taguchi, K., Matsubara, K., Nakahara, K., Kato, D., Sogawa, K., and Oka, H. (2016) Inactivation of Airborne Bacteria and Viruses Using Extremely Low Concentrations of Chlorine Dioxide Gas. Pharmacology, 97, 301-306.

Okuda, S., Shimasaki, N., and Okaue, A. (2008) The evaluation method of the removal and bactericidal devices for the airborne microbes. (in Japanese) Indoor Environment, 11, 21-26.

Schaffer F. L., Soergel, M. E., and Straube, D. C. (1976) Survival of airborne influenza virus: effects of propagating host, relative humidity, and composition of spray fluids. Arch. Virol., 51, 263-273.

Shimasaki, N., Hara, M., Kikuno, R., and Shinohara, K. (2016a) A highly sensitive assay using synthetic blood containing test microbes for evaluation of the penetration resistance of protective clothing material under applied pressure. Biocontrol Sci., 21, 141-152.

Shimasaki, N., Nojima, Y., Okaue, A., Takahashi, H., Kageyama, T., Hamamoto, I., and Shinohara, K. (2016b) A Novel Method of Safely Measuring Influenza Virus Aerosol Using Antigen-Capture Enzyme-Linked Immunosorbent Assay for the Performance Evaluation of Protective Clothing Materials. Biocontrol Sci., 21, 81-89.

Shimasaki, N., Okaue, A., Kikuno, R., Okuda, S., and Abe, K. (2015) Development of a new technique using glass beads for dry dispersion of airborne fungal spores. Biocontrol Sci., 20, 53-58.

Turgeon, N., Toulouse, M. J., Martel, B., Moineau, S., and Duchaine, C. (2014) Comparison of five bacteriophages as models for viral aerosol studies. Appl. Environ. Microbiol., 80, 4242-4250.

Turgeon, N., Michel, K., Ha, T., L., Robine, E., Moineau, S., and Duchaine, C. (2016) Resistance of Aerosolized Bacterial Viruses to Four Germicidal Products. PLOS ONE, 11, e0168815.

Trouwborst, T. and Kuyper, S. Inactivation of bacteriophage T3 in aerosols: effect of prehumidification on survival after spraying from solutions of salt, peptone, and saliva. (1974) Appl. Microbiol., 27, 834-837.

Verreault, D., Marcoux-Voiselle, M., Turgeon, N., Moineau, S., and Duchaine, C. (2015) Resistance of Aerosolized Bacterial Viruses to Relative Humidity and Temperature. Appl. Environ. Microbiol., 81, 7305-7311.

Yoneyama, T., Kiyohara, T., Shimasaki, N., Kobayashi, G., Ota, Y., Notomi, T., Totsuka, A., and Wakita, T. (2007) Rapid and real-time detection of hepatitis $A$ virus by reverse transcription loop-mediated isothermal amplification assay. J. Virol. Methods, 145, 162-168.

Zhang, H., Yoshino, H., Murakami, S., Bogaki, K., Tanaka, T., Akabayashi, S., and Abe, K. (2009) Analyses of indoor humidity environment in nationally resident houses of Japan. (in Japanese) AlJ J. Technol. Des., 15, 453-457. 